\title{
BMJ Open Psychometric properties of an Arabic- language health literacy assessment scale for adolescents (HAS-A-AR) in Palestine
}

\author{
Mohammed B A Sarhan (D) , ${ }^{1}$ Harry S Shannon, ${ }^{2}$ Rika Fujiya, ${ }^{3}$ \\ Masamine Jimba (i) , ${ }^{1}$ Rita Giacaman ${ }^{4}$
}

To cite: Sarhan MBA, Shannon HS, Fujiya R, et al. Psychometric properties of an Arabic-language health literacy assessment scale for adolescents (HAS-A$\mathrm{AR})$ in Palestine. BMJ Open 2020;10:e034943. doi:10.1136/ bmjopen-2019-034943

- Prepublication history and additional material for this paper are available online. To view these files, please visit the journal online (http://dx.doi. org/10.1136/bmjopen-2019034943).

Received 15 October 2019 Revised 10 March 2020 Accepted 08 May 2020

Check for updates

(C) Author(s) (or their employer(s)) 2020. Re-use permitted under CC BY-NC. No commercial re-use. See rights and permissions. Published by BMJ.

${ }^{1}$ Department of Community and Global Health, Graduate School of Medicine, The University of Tokyo, Bunkyo-ku, Tokyo, Japan ${ }^{2}$ Department of Health Research Methods, Evidence \& Impact, Faculty of Health Sciences, McMaster University, Hamilton, Ontario, Canada

${ }^{3}$ Faculty of Nursing and Medical Care, Keio University, Fugisawa, Kanagawa, Japan

${ }^{4}$ Institute of Community and Public Health, Birzeit University, Birzeit, State of Palestine

Correspondence to Professor Masamine Jimba; mjimba@m.u-tokyo.ac.jp

\section{ABSTRACT}

Objectives Health literacy research in Palestine is limited, and a locally validated tool for use among adolescents has been unavailable until now. Therefore, this study aimed to adapt health literacy assessment scale for adolescents (HAS-A) into Arabic language (HAS-A-AR) and Palestinian context and to investigate its psychometric properties.

Design We conducted a cross-sectional household survey using a stratified random sample and household face-toface interviews.

Setting and participants We conducted 1200 interviews with sixth to ninth graders in the Ramallah and al-Bireh district of the West Bank, Palestine in 2017.

Methods We translated and adapted HAS-A to be sensitive to the Palestinian context and tested its psychometric properties. We evaluated face and content validity during the back-translation process and checked for construct validity through exploratory factor analysis (EFA). We tested for internal consistency using Cronbach's alpha, MacDonald's omega test and the greatest lower bound (GLB). Furthermore, we calculated the scale's average inter-item correlation.

Results EFA revealed that HAS-A-AR has a similar structure to the original HAS-A. It extracted three factors (communication, confusion and functional health literacy) whose eigenvalues were $>1$. Together they explained $57 \%$ of the total variance. The proportions of adolescents with high levels of communication, confusion and functional health literacy were $45 \%, 68 \%$ and $80 \%$, respectively. Cronbach's alpha, MacDonald's omega and the GLB values for communication subscale were $0.87,0.88$ and 0.90 , and they were $0.78,0.77$ and 0.79 for confusion subscale, while they were $0.77,0.77$ and 0.80 , respectively, for functional healthy literacy subscale. The average inter-item correlation for the subscales ranged between 0.36 and 0.59 .

Conclusion HAS-A-AR is a valid and reliable health literacy measuring instrument with appropriate psychometric properties. HAS-A-AR is currently available for use among adolescents in Palestine and the surrounding Arab countries with similar characteristics as Palestine, including language, culture and political instability.
Strengths and limitations of this study

- This is the first study in Palestine which aimed to assess Palestinian adolescent health literacy.

- We validated the Arabic version of a health literacy assessment scale (HAS-A-AR) by adding an extra option to each item of the original questionnaire to be sensitive to the Palestinian context.

- We used various tests to measure HAS-A-AR psychometric properties including face, content and construct validity.

- For internal consistency, we used Cronbach's alpha, MacDonald's omega and the greatest lower bound; however, we did not perform test-retest reliability analysis.

- We did not perform a criterion validity test due to the lack of a gold standard tool.

\section{INTRODUCTION}

Health literacy is gaining attention globally, and it is becoming a priority to governments, health sectors and researchers. ${ }^{12}$ It can help individuals engage in health-promoting activities, participate in screening programmes and use preventive services. ${ }^{3}$ Sørensen $e t$ al stated that 'health literacy entails people's knowledge, motivation and competencies to access, understand, appraise, and apply health information in order to make judgments and take decisions in everyday life concerning healthcare, disease prevention and health promotion to maintain or improve quality of life during the life course'. ${ }^{4}$ In this definition, they captured all the essential aspects of the health literacy concept by focusing on public health and medical approaches and emphasising on health literacy's vital skills that are necessary to navigate through the complex demands of health in the current modern societies. ${ }^{3}$ These required skills should be more than basic reading and numeracy skills, 
as emphasised by some of the available health literacy measures. ${ }^{5}$ Health literacy has to be more comprehensive by including communication, understanding, problem solving and decision-making skills. ${ }^{5}$

Health literacy needs to be approached from a public health perspective, ${ }^{6}$ an approach that has been recognised by the WHO in 2016 which considered health literacy as a public health goal to be achieved. ${ }^{7}$ Consequently, the education system-besides the health system and society-is increasingly becoming a central piece of developing students' health literacy. ${ }^{8}$ It is believed that health education within schools is necessary to equip students with knowledge, skills and competencies, which is designed to change their behaviours and attitudes. ${ }^{9}$ In other words, including health literacy in school programmes can ensure that students acquire what they need to take care of their own health. ${ }^{10}$

Adolescents gain more autonomy at this stage of their lives, ${ }^{11}$ becoming more aware of their rights and more ready to take decisions on their own. ${ }^{11}{ }^{12}$ Combining these changes with improvements in adolescents' health literacy may not only influence their critical thinking and decision-making abilities, health status and well-being, but also bring benefits to the local community by helping students to be responsible and productive citizens and become more efficient users of services, ${ }^{10}{ }^{13}$ especially medical services by learning the necessary skills to navigate the healthcare system, critically assess health information and receive better healthcare. ${ }^{14}$

Despite its increase in the past decade, health literacy research related to adolescents is still limited in the literature, ${ }^{1115} 16$ likely because good quality tools to measure it are not available for this age group. ${ }^{15}$ In the Middle East, health literacy research has increased recently as well. However, few studies have focused on testing the psychometric properties of health literacy instruments and have measured health literacy levels among adolescents. ${ }^{17-19}$ For example, the Health Literacy Measure for Adolescents (HELMA) ${ }^{17}$ and the Health Literacy for SchoolAged Children (HLSAC-T) scale ${ }^{19}$ were developed and tested for their psychometric properties in Persian and Turkish languages, respectively. However, health literacy is under-researched in the Arab world, which reflects the unavailability of validated tools in the Arabic language which measure and assess adolescent health literacy. ${ }^{1}$ In Lebanon, a study validated the Arabic versions of the Rapid Estimate of Adult Literacy in Medicine revised and the Short Test of Functional Health Literacy for Adults (S-TOFHLA). ${ }^{1}$ In Saudi Arabia, a study validated the Arabic Rapid Estimate of Adult Literacy in Dentistry 30, ${ }^{20}$ while an Iraqi survey validated the Newest Vital signs and S-TOFHLA in Iraq. ${ }^{21}$ Moreover, in Egypt, a study used the Arabic versions of the Swedish Functional Health Literacy scale and the European Health Literacy Survey Questionnaire Q16 among patients older than 15 years attending a tertiary healthcare facility. ${ }^{2}$ Finally, the health literacy of Palestinian adult patients with type 2 diabetes mellitus was studied recently in Palestine. ${ }^{22} 23$ In the Arab World, the adapted health literacy scales are mainly targeting adults, not adolescents.

The Health Assessment Scale for Adolescents (HAS-A) is a self-reported scale for assessing the health literacy of adolescents. HAS-A is a tool generated by including children from both clinical and community settings and it was validated in New York. The main difference between HAS-A and other health scales such as HELMA or HLSAC-T is that HAS-A evaluates specifically adolescent ability to navigate the healthcare system, including the communication process with their doctors about health issues or knowledge regarding medicines or illnesses. Moreover, the original English-language HAS-A was validated among a group of adolescents with a wide range of ages (12-19 years old). According to Manganello et al, using the HAS-A to assess adolescents' health literacy in medical or school settings could help to provide adequate health promotion and healthcare activities. ${ }^{11}$

In Palestine, adolescents suffer from the negative impacts of chronic political conflict, ${ }^{6}$ such as chronic stress and mental health problems. They may also suffer from various health-related problems, including malnutrition, accidents, disabilities and compromised accessibility to healthcare.${ }^{24}$ Health literacy may help Palestinian adolescents to reduce the negative health impact of chronic exposure to violence. ${ }^{6}$ However, the paucity of work on health literacy in adolescents and the scarcity of the validated Arabic-language health literacy scales for adolescents in Palestine limit the possibilities to address health literacy and its determinants among the Palestinian adolescents. Therefore, this study was conducted to (i) translate the HAS-A into Arabic; (ii) adapt the scale to be sensitive to the Palestinian socio-economic context and (iii) measure the psychometric properties of the new scale among Palestinian adolescents.

\section{METHODS \\ Measurement of demographic and socio-economic characteristics}

We measured demographic and socio-economic characteristics by asking adolescents about their sex, age, grade finished in previous academic year, school average description (student's self-report of performance), educational level of mother and father, occupation of mother and father, family financial status and access to the internet.

\section{Health literacy assessment scale for adolescents}

HAS-A includes 15 questions that are divided into three subscales: communication, confusion and functional health literacy. Communication subscale focuses on oral communication and comfort when asking questions to healthcare professionals (HCPs); confusion subscale focuses on the degree of confusion about received health information and functional health literacy evaluates reading ability and numeracy. For each subscale, adolescents had to choose among one of the following 
options (always $=4$, usually $=3$, sometimes $=2$, rarely $=1$ and never $=0$ ) for each item of the HAS-A. However, to adapt the HAS-A to the Palestinian context, we added a sixth option to each item to reflect the fact that HCPs tend to talk about the adolescent health with parents rather than directly with the adolescent. For example, we added the option 'Doctor does not ask me' to the question 'How often your doctor seems to understand you when you answer a question he or she asks?'. These added responses were given the same value as 'Never' for calculating scores. We calculated scores by summing responses of the items. The range of the possible scores for each subscale is ' $0-20$ ' for communication subscale, ' $0-16$ ' for confusion subscale and ' $0-24$ ' for functional health literacy subscale. Having a higher score in the communication subscale indicates having better communication skills and better health literacy. A higher score in the confusion subscale means that adolescents have a greater confusion about health information, which suggests having lower health literacy levels. For the functional health literacy subscales, a higher score indicates lower health literacy as a result of lower ability to read health information and understand numbers. We considered those who scored ' $15-20$ ' in the communication subscale, ' $0-7$ ' in the confusion subscale and ' $0-11$ ' in the functional health literacy subscale as having a 'high health literacy level'. ${ }^{11}$

\section{Translation and adaptation of HAS-A}

We based our translation methods and cultural adaptation of scales on the model created by Wild et $a l^{25}$ (figure 1). In our study, the research team held several discussions to obtain an in-depth understanding of the HAS-A and to translate and culturally adapt it. Following the preparation stage, a native Arabic speaker who is fluent in English translated the scale into Arabic, and then two main researchers from Palestine reviewed the Arabic translation separately, followed by several discussions until they reached agreement and reconciliation of the two revisions, which produced the final forward translated version of the HAS-A.

We followed the same approach in the back-translation process, as a native English speaker who is fluent in Arabic back-translated the reconciled Arabic version into English. Again two main researchers reviewed the back translation separately, reaching an agreement as to its appropriateness. The two researchers met to compare the back-translated version with the original HAS-A version, agreeing that the final translated version was conceptually equivalent to the original one. Next, we piloted the Arabic version among 30 adolescents ( 15 boys and 15 girls) who were in sixth to ninth grades in 2017. We ensured that they came from all localities (urban, rural and refugee camps). We measured the duration of interviews and checked questions for clarity and comprehensibility. This was done by taking into consideration reading the interviewer's report on the interviews and by asking the adolescents if they found any difficulty in understanding or answering any questions. Based on the pilot results and expert opinions, we made final adjustments to the questionnaire.

\section{Design and sampling}

This survey targeted Palestinian households with adolescents who finished sixth to ninth grades in 2017 and who were living in the Ramallah and al-Bireh district of the West Bank. We followed a cross-sectional household survey design. To identify a representative sample, we divided the Ramallah and al-Bireh district into three strata according to locality type: urban, rural and refugee camps. We obtained a list of all locations within each locality type from the Palestinian Central Bureau of Statistics. We chose a random sample of urban, rural and Palestinian refugee camp locations to include in this study. Each location was divided into geographical cells to facilitate the process of data collection, and each cell contained almost 150 households. We then chose a random sample of cells from each selected location. We included 60 cells in this study, 23 urban, 22 rural and 15 refugee camps, randomly choosing 20 households from each cell. Whenever we found more than one child between the ages of 11-16 years in the household, we used the Kish grid method to choose one child randomly. As the number of Palestinian refugee camp residents was low compared with urban and rural areas, we oversampled respondents from refugee camps. The final sample of 1200 consisted of 460 urban, 440 rural and 300 camp households. Given the unequal probabilities of selecting respondents, we calculated the sample weights. The overall probability of choosing any adolescent was the product of the probabilities of choosing a cell within the locality $\left(\mathrm{P}_{\mathrm{c}}\right)$, choosing a household within the cell $\left(\mathrm{P}_{\mathrm{h}}\right)$, choosing a household including at least one age-eligible child $\left(\mathrm{P}_{\mathrm{e}}\right)$ and choosing the child within the household $\left(\mathrm{P}_{\mathrm{a}}\right)$. The sample weight was the inverse of this overall probability.

Probability of choosing an adolescent $\left(\mathrm{P}_{\text {tot }}\right)=\mathrm{P}_{\mathrm{c}} * \mathrm{P}_{\mathrm{h}} * \mathrm{P}_{\mathrm{e}} * \mathrm{P}_{\mathrm{a}}$

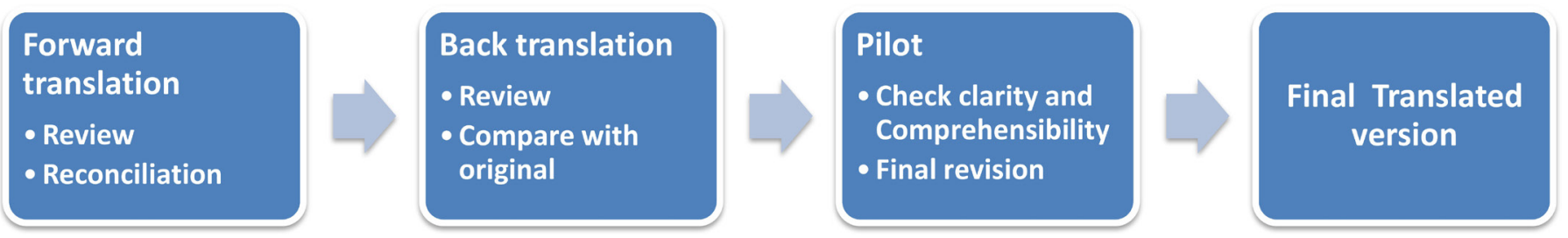

Figure 1 The process followed for translating and adapting the Arabic health literacy assessment scale for adolescents. 
Evaluation of the psychometric properties of Arabic health literacy assessment scale for adolescents

To evaluate the psychometric properties of Arabic health literacy assessment scale for adolescents (HAS-A-AR), we used different validity methods. First, we evaluated face and content validity during the translation process. A group of experts revised the HAS-A several times during the back-translation process. ${ }^{26}$ Those experts were members of the research team and an official from the Ministry of Education. To check the construct validity, we performed an exploratory factor analysis (EFA) ${ }^{27} 28 \mathrm{We}$ used the entire data set for EFA. We did not do a formal sample size calculation in advance, but a sample of 1000 or more is considered to be excellent for EFA. ${ }^{29}$ For sampling adequacy of the EFA, we used the Kaiser-Meyer-Olkin $(\mathrm{KMO})$ test $(\mathrm{KMO}>0.50)$ and Bartlett's test of sphericity ( $p$ value $<0.05$ ).$^{30}$ To check for the absence of multicollinearity, we checked if the determinant value was higher than $0.00001 .^{31}$ Moreover, we used anti-image correlations to determine if reliable factors could be generated (cut-off >0.5) ${ }^{31}$ To determine the number of factors, we used a scree plot and Kaiser's criterion (eigenvalues $>1$ ), which states that items with eigenvalues $>1$ should be retained. ${ }^{31}$ However, we also performed a confirmatory factor analysis (CFA) on the same sample to check the overall goodness fit of model. ${ }^{32}$ To evaluate the overall model fitness, we calculated the $\chi^{2}$ statistic, which should have a $\mathrm{p}$ value $>0.05$. We also measured root mean square error of approximation (RMSEA) that has to be $<0.6$. Additionally, we looked at the values of the Tucker-Lewis index (TLI) and comparative fit index (CFI), both have to be $\geq 0.9$. Finally, we calculated the standardised root mean square residual (SRMR), which is preferable to be $<0.1{ }^{27}$ To determine the reliability, we used various measures: we tested for internal consistency using Cronbach's alpha, ${ }^{33}$ MacDonald's omega test ${ }^{34}$ and greatest lower bound (GLB) ${ }^{35}$ Furthermore, we calculated inter-item correlations, ${ }^{36}{ }^{37}$ average inter-item correlation $^{38}{ }^{39}$ and item-rest correlations ${ }^{36}{ }^{40}$ (table 1). We followed complete case analysis (exclude list-wise) to deal with missing data during the analysis process. ${ }^{41}$

\section{Statistical analysis}

We used the JASP V.0.9.2.0 software to calculate MacDonald's omega and GLB, while we used IBM SPSS V.24

\begin{tabular}{|c|c|}
\hline Reliability statistics & Criteria \\
\hline $\begin{array}{l}\text { Cronbach's alpha } \\
\text { MacDonald's omega }\end{array}$ & $>0.7^{314546}$ \\
\hline \multicolumn{2}{|l|}{ Greatest lower bound } \\
\hline Inter-item correlations & $>0.3^{32}$ \\
\hline Average inter-item correlation & Between 0.15 and $0.50^{35}$ \\
\hline $\begin{array}{l}\text { Item-rest or item-to-total } \\
\text { correlations }\end{array}$ & $>0.4^{36}$ \\
\hline
\end{tabular}

software to perform all other statistical analytical procedures including the descriptive analysis of the sample characteristics, HAS-A-AR scores and health literacy levels, taking into consideration the sampling weights.

\section{Ethical approval}

We informed adolescents of what this study was about, why we were conducting this study, that they were not obliged to participate in this study if they did not wish to, that they were able to refuse to answer any question they did not want to answer and that they could withdraw from this study any time they wished. We obtained adolescent's oral consent following disclosure and explanation, with field workers signing the disclosure form confirming that they have read the disclosure form and that they have obtained oral consent from participants. Oral consent (in non-invasive procedures) is what the Research Ethics Committee at Birzeit University guidelines stipulate, given that local experience indicates that people become suspicious and ill at ease if you ask them to sign their names on paper.

\section{Patient and public involvement}

It was not appropriate or possible to involve patients or the public in the design, or conduct, or reporting, or dissemination of our research.

\section{RESULTS}

\section{Sample characteristics}

Almost 99\% of approached households agreed to participate in this study. Fifty-one per cent of the adolescents in this study were girls, with an average age of 13.5 (1.1) years. The majority had completed at least sixth grade (primary school) at the time of interview. More than half of them $(61 \%)$ reported having 'very good' or 'excellent' school averages. Almost $30 \%$ and $26 \%$ of their mothers and fathers had higher than high school education, respectively. The majority (92\%) reported that their fathers were currently employed compared with $30 \%$ of mothers who were working outside the home (employed). Internet was available to almost $87 \%$ of households (table 2).

\section{Arabic health literacy assessment scale for adolescents}

We summarised the results of HAS-A-AR in tables 3 and 4. The HAS-A scales results showed that only $45 \%$ of adolescents had a high level of health literacy in terms of interpersonal communication. However, almost $68 \%$ of them showed high levels of health literacy according to HAS-A-AR confusion subscale, while $80 \%$ showed high health literacy in their ability to read and understand health information (table 3). The context-related categories that we added to HAS-A-AR scale items showed a wide range of frequencies. Some items had relatively low rates such as 'How often does your doctor seem to understand you when you answer a question he or she asks?', for which around $7 \%$ responded that their doctor does not ask them any questions. Others showed high frequencies 
Table 2 Sociodemographic characteristics of adolescents

\section{Demographic}

\begin{tabular}{|c|c|c|c|}
\hline variables & Categories & $\mathbf{N}$ & $\%$ * \\
\hline \multirow[t]{2}{*}{ Gender } & Male & 590 & 49 \\
\hline & Female & 610 & 51 \\
\hline \multirow[t]{5}{*}{ Age group } & 11 to 12 years & 21 & 1.8 \\
\hline & 12 to $<13$ & 399 & 33.2 \\
\hline & 13 to $<14$ & 272 & 22.7 \\
\hline & 14 to $<15$ & 292 & 24.3 \\
\hline & $15-16$ & 216 & 18.0 \\
\hline \multirow{5}{*}{$\begin{array}{l}\text { Class graduated } \\
\text { from previous year } \\
n=1197\end{array}$} & 6 th grade & 374 & 31.3 \\
\hline & 7 th grade & 277 & 23.2 \\
\hline & 8th grade & 285 & 23.8 \\
\hline & 9th grade & 254 & 21.2 \\
\hline & Left school & 7 & 0.6 \\
\hline \multirow{5}{*}{$\begin{array}{l}\text { School average } \\
\text { description } \\
n=1197\end{array}$} & Excellent & 292 & 24.4 \\
\hline & Very good & 444 & 37.1 \\
\hline & Good & 315 & 26.3 \\
\hline & Fair & 110 & 9.2 \\
\hline & Poor & 35 & 2.9 \\
\hline \multirow{3}{*}{$\begin{array}{l}\text { Mother's educational } \\
\text { level } \\
n=1136\end{array}$} & Not educated & 37 & 3.2 \\
\hline & $\begin{array}{l}\text { Educated till high } \\
\text { school }\end{array}$ & 756 & 66.5 \\
\hline & $\begin{array}{l}\text { Higher than high } \\
\text { school }\end{array}$ & 343 & 30.2 \\
\hline \multirow{3}{*}{$\begin{array}{l}\text { Father's educational } \\
\text { level } \\
n=1199\end{array}$} & Not educated & 41 & 3.8 \\
\hline & $\begin{array}{l}\text { Educated till high } \\
\text { school }\end{array}$ & 775 & 70.4 \\
\hline & $\begin{array}{l}\text { Higher than high } \\
\text { school }\end{array}$ & 285 & 25.9 \\
\hline \multirow[t]{3}{*}{ Mother has job } & Yes & 359 & 29.9 \\
\hline & No & 839 & 69.9 \\
\hline & Do not know & 2 & 0.2 \\
\hline \multirow{3}{*}{$\begin{array}{l}\text { Father has job } \\
n=1199\end{array}$} & Yes & 1103 & 92.0 \\
\hline & No & 90 & 7.5 \\
\hline & Do not know & 6 & 0.5 \\
\hline \multirow[t]{2}{*}{ Internet access } & Yes & 1038 & 86.5 \\
\hline & No & 162 & 13.5 \\
\hline
\end{tabular}

*Weighted percentages.

such as 'How often do you think the forms you complete at your doctor's office are confusing?', for which $54 \%$ of the adolescents reported that they do not complete forms at the doctor's office (table 4).

\section{Psychometric properties of HAS-A-AR Validity}

Face and content validity testing revealed that all items were understandable with minor modifications made. Based on the scree plot and eigenvalues, we decided to retain three factors (figure 2). We performed EFA using the principal axis factoring method of extraction. The overall KMO statistic was 0.89 , while Bartlett's test of sphericity was significant $\left(\chi^{2} \quad(1200)=6505.6, p<0.001\right)$. Anti-image correlation matrix diagonal values were all $>0.8$. We found that our sample did not have the issue of multicollinearity. Factor 1 (communication) included five items that explained $33 \%$ of the variance with factor loadings range from 0.62 to 0.82 . Factor 2 (functional health literacy) included six items that explained $17 \%$ of the total variance with loadings range between 0.40 and 0.76 , while factor 3 (confusion) included four items that explained $7 \%$ of the total variance with loadings between 0.47 and 0.83 . Even though the $\mathrm{p}$ value for the $\chi^{2}$ statistic was low $\left(\chi^{2}=426.42, \mathrm{p}<0.001\right)$, other goodness of fit measures showed that the model had a good fit. RMSEA was 0.57 . TLI and CFI values were 0.95 and 0.94 , respectively, while SRMR was 0.038 .

\section{Reliability analysis}

Reliability analysis showed that HAS-A-AR, which consists of 15 items, is a reliable scale (alpha $=0.85$, omega $=0.88$, $\mathrm{GLB}=0.90$ ) (for details on alpha, omega and GLB of HASA-AR subscales, see table 3). Inter-item correlations for all items of factors 1 and 3 were $>0.3$, while in factor 2 inter-item correlations between item 3.5 and items 3.1 and 3.2 were slightly below 0.3 (online supplementary 1). Average inter-item correlation for all HAS-A-AR scales combined is 0.28 . The average inter-item correlation for the subscales range was between 0.36 and 0.59 . Item-rest correlations were all above 0.4 (table 4 ).

\section{DISCUSSION}

In this study, we applied published methods for translation of the HAS-A to provide an Arabic version of this tool (HAS-A-AR). Adolescents clearly understood the translated version, and testing its psychometric properties showed that HAS-A-AR is a valid and reliable tool to be used for measuring health literacy among Palestinian adolescents living in the Ramallah District.

\section{Psychometric properties}

Adding the extra options in HAS-A-AR which are relevant to the Palestinian context did not change the factor structure. The initial step of validation of the Arabic version of HAS-A-AR was testing the factorial structure. ${ }^{42}$ EFA revealed that HAS-A-AR has a similar structure to the original HAS-A, which supports the usage of similar scoring methods. Solid and stable factors need to have minimum factor loadings between 0.4 and $0.5 .^{12} 27$ All of the factor loadings were $>0.5$ except two, which were $\geq 0.4$. Therefore, we retained all the original HAS-A items. Around $57 \%$ of the variance is explained by the three retained factors, which is close to $60 \%$, the value that Hair et al reported as acceptable to consider the construct to be valid. ${ }^{36}$ This pattern of factor loadings and model 
Table 3 Descriptive results and reliability of three subscales of HAS-A-AR

\begin{tabular}{lccc} 
& Communication & Confusion* & Functional health literacy† \\
\hline Mean & $13(5.3) \ddagger$ & $5.4(3.8) \ddagger$ & $7(4.9) \ddagger$ \\
Median & 14 & 5 & 6 \\
Minimum possible & 0 & 0 & 0 \\
Maximum possible & 20 & 16 & 24 \\
High health literacy§ & $539(44.9 \%) \ddagger$ & $826(68.8 \%) \ddagger$ & $960(80.3 \%) \ddagger$ \\
Low health literacy & $661(55.1 \%) \ddagger$ & $374(31.2 \%) \ddagger$ & $236(19.7 \%) \ddagger$ \\
Cronbach's alpha & 0.87 & 0.78 & 0.77 \\
McDonald's omega & 0.88 & 0.77 & 0.77 \\
Greatest lower bound & 0.90 & 0.79 & 0.80 \\
Average inter-item correlation & 0.59 & 0.45 & 0.36 \\
\hline
\end{tabular}

${ }^{\star} \mathrm{N}=1199$.

$\dagger \mathrm{N}=1196$.

$\ddagger$ Weighted means and percentages.

$\S$ High health literacy subscales' scores: communication (15-20), confusion (0-7) and functional health literacy (0-11).

HAS-A-AR, Arabic health literacy assessment scale for adolescents.

fit suggests that the HAS-A-AR has adequate construct validity.

Cronbach's alpha values suggest that HAS-A-AR has good internal consistency. Compared with the reliability testing of the original HAS-A, ${ }^{11}$ the Arabic version showed a higher Cronbach's alpha for the communication and confusion subscales and was similar for the functional health literacy subscale. However, in the literature, there is some debate regarding the adequacy of Cronbach's alpha to assess the reliability of scales, especially those with ordinal items, as this may bias the measured reliability of the tested scale. ${ }^{43}$ Alternatives, such as MacDonald's omega test ${ }^{34}$ and GLB ${ }^{35}$ as preferable to Cronbach's alpha, were suggested. Since authors are recommended to report reliability estimates other than Cronbach's alpha, ${ }^{44}$ we measured MacDonald's omega, GLB and Cronbach's alpha (for comparability with other studies). Values of reliability measures, which are higher than 0.7 , indicate that the scale is reliable. ${ }^{334546}$ Therefore, our results suggest that HAS-A-AR is a reliable instrument to be used in this population.

Furthermore, the average inter-item correlations also indicate good internal consistency. The recommended range of average inter-item correlation is between 0.15 and $0.5{ }^{47}$ The confusion and functional health literacy subscales' average inter-item correlations were within the recommended range, while the communication subscale's average inter-item correlation was slightly higher than 0.5 . This indicates that items in the confusion and functional health literacy, and to a lower extent the communication subscale, are homogeneous enough to describe the same construct but still have their unique variance that distinguishes one from the other. In general, these results provide additional support for the reliability of the measure.

\section{Health literacy}

In this study, the percentage of adolescents choosing the added responses, which expressed a lack of active involvement with their healthcare, was relatively high in most questions. We expected such a pattern, as it emphasises a gap in interaction and communication between the Palestinian adolescents and their HCPs. The quality of communication with HCPs is also essential, especially to the subsequent empowerment of individuals, as the way of communicating can be a facilitator or a barrier for health information exchange. ${ }^{48}$ Neuroscience research indicates that adolescents can possess adequate communication skills essential for their ability to make medical or healthrelated decisions. ${ }^{48}$ Good communication between the Palestinian adolescents and their HCPs has to be created to enhance adolescents' health literacy competencies, which may impact on the received healthcare services quality.

Moreover, adolescents in this study showed a low level of health literacy. Compared with American adolescents, ${ }^{11}$ the adolescents of this study had similar levels of functional health literacy, but they reported lower communication skills and were more likely to be confused regarding health information. This could be because Palestinian adolescents lack the autonomy to participate actively in decision-making regarding their health. Parents usually have the power to communicate directly with HCPs and make health-related decisions on behalf of their children. However, it is worth noting that being in control can enhance the feeling of confidence, which in turn will contribute to an active role and involvement in health. ${ }^{49}$ The age of 12 might be when adolescents start to possess the competencies for that enable to have an active role in medical or health-related decision-making. ${ }^{48}$ In the Netherlands, 12-17-year-old adolescents expressed their desire to be involved in health-related decision-making 
Table 4 HAS-A-AR items and their psychometric properties

HAS-A items with the added responses

Factor loading

Reliability

Items*

Added response

Weighted

$\%$ of added

\begin{tabular}{ll} 
& Items $^{*}$ \\
\hline 1.1 & $\begin{array}{l}\text { How often is it easy for you to ask } \\
\text { your doctor questions about your } \\
\text { health? } \\
\mathrm{n}=1200\end{array}$
\end{tabular}

response

F1† F2

There is no special doctor 18.6

0.62

0.61

understand what you mean when you

ask him or her a question about your

health? $n=1200$

\begin{tabular}{|c|c|c|c|c|c|}
\hline 1.3 & $\begin{array}{l}\text { How often can you easily describe } \\
\text { a health problem you have to your } \\
\text { doctor? } \\
n=1200\end{array}$ & $\begin{array}{l}\text { Not me who describes } \\
\text { my health problem for the } \\
\text { doctor }\end{array}$ & 10.4 & 0.82 & 0.73 \\
\hline
\end{tabular}

$\begin{array}{lllll}1.5 & \text { How often do you understand the } & \text { I don't ask the doctor any } & 8.1 \S & 0.79 \\ \text { answers your doctor gives to your } & \text { questions } \\ \text { questions? } & & \\ n=1199\end{array}$

$\begin{array}{lllll}2.1 & \text { How often do you get confused } & \text { I don't search/find } & 15.3 & 0.49\end{array}$
because you find different information information about the same health topic? $\mathrm{n}=1200$

\begin{tabular}{|c|c|c|c|c|c|c|}
\hline 2.2 & $\begin{array}{l}\text { How often do you get confused when } \\
\text { your doctor tells you about taking } \\
\text { medicine? } \\
n=1200\end{array}$ & $\begin{array}{l}\text { The doctor doesn't talk } \\
\text { with me about medicine }\end{array}$ & 14.3 & & 0.72 & 0.58 \\
\hline 2.4 & $\begin{array}{l}\text { How often do you get confused } \\
\text { when your doctor tells you about test } \\
\text { results, like results of an X-ray*? } \\
n=1199\end{array}$ & $\begin{array}{l}\text { The doctor doesn't tell } \\
\text { me about test results, like } \\
\text { results of an X-ray* }\end{array}$ & $28.1 \S$ & & 0.56 & 0.55 \\
\hline 3.1 & $\begin{array}{l}\text { How often do you get confused when } \\
\text { reading instructions for medicine? } \\
n=1200\end{array}$ & $\begin{array}{l}\text { I don't read instructions for } \\
\text { medicine }\end{array}$ & 29.1 & 0.40 & & 0.5 \\
\hline 3.3 & $\begin{array}{l}\text { How often do you think the forms you } \\
\text { complete at your doctor's office are } \\
\text { confusing? } \\
n=1199\end{array}$ & $\begin{array}{l}\text { I don't complete forms at } \\
\text { my doctor office }\end{array}$ & $54.1 \S$ & 0.55 & & 0.54 \\
\hline
\end{tabular}

Continued 


\begin{tabular}{|c|c|c|c|c|c|c|c|}
\hline & \multicolumn{3}{|l|}{ HAS-A items with the added responses } & \multicolumn{3}{|c|}{ Factor loading } & \multirow[t]{2}{*}{ Reliability } \\
\hline & Items* & Added response & $\begin{array}{l}\text { Weighted } \\
\% \text { of added } \\
\text { response }\end{array}$ & F1† & F2 $\ddagger$ & F3† & \\
\hline 3.4 & $\begin{array}{l}\text { How often are you confused by health } \\
\text { information that has a lot of numbers } \\
\text { and statistics? } \\
n=1198\end{array}$ & $\begin{array}{l}\text { I don't read such health } \\
\text { information }\end{array}$ & 37.89 & & 0.62 & & 0.55 \\
\hline 3.5 & $\begin{array}{l}\text { When you talk to people other than } \\
\text { your doctor about health issues, how } \\
\text { often are you confused by what they } \\
\text { tell you? } \\
n=1200\end{array}$ & $\begin{array}{l}\text { I don't talk to other people } \\
\text { than my doctor }\end{array}$ & 22.7 & & 0.54 & & 0.46 \\
\hline 3.6 & $\begin{array}{l}\text { When reading brochures or handouts* } \\
\text { about health issues, how often do } \\
\text { you need someone to help you read } \\
\text { them? } \\
n=1200\end{array}$ & $\begin{array}{l}\text { I don't read brochures or } \\
\text { handouts about health } \\
\text { issues }\end{array}$ & 30.3 & & 0.76 & & 0.53 \\
\hline
\end{tabular}

Eigenvalue: factor $1=4.937$ (33\% of variance), factor $2=2.570$ ( $17 \%$ of variance) and factor $3=1.095$ ( $7 \%$ of variance).

Extraction method: principal axis factoring.

Rotation method: Promax with Kaiser normalisation.

Determinant $=0.04$.

Kaiser-Meyer-Olkin measure of sampling adequacy $=0.886$.

${ }^{*} \mathrm{HAS}-\mathrm{A}$ original English-language questions.

$\dagger 1199$ were used, 1 was excluded list-wise.

$\ddagger 1196$ were used, 4 were excluded list-wise.

§One missing case.

१Two missing cases.

HAS-A, health literacy assessment scale for adolescents; HAS-A-AR, Arabic health literacy assessment scale for adolescents; IRC, Item-rest correlation (item-total correlation).

with advice from their parents. ${ }^{50}$ For adolescents, this is not only a matter of taking the right decision, but also the feeling of autonomy and having control over their own health. ${ }^{51}$ For example, patient-centred communication with 10-15-year-old type 1 diabetic adolescent patients increased the adolescents and parents perceptions of competence, self-efficacy and perceived control, which led to increased adherence and metabolic control. ${ }^{52}$

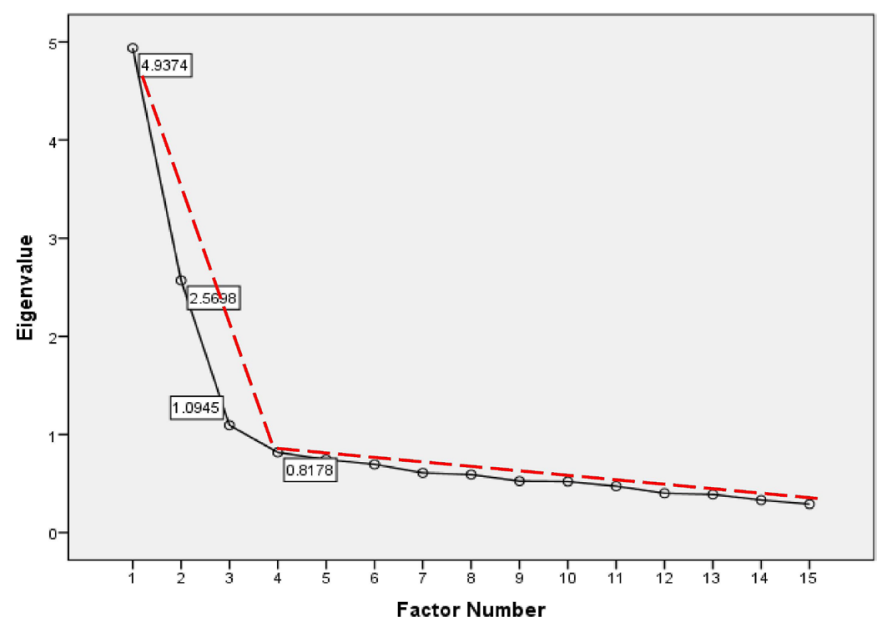

Figure 2 Scree plot and the eigenvalues of the three retained factors and one non-retained factor.
Therefore, encouraging shared decision-making between parents and their adolescent children may help in improving adolescent health literacy levels.

\section{Strengths and limitations}

Using a representative sample of Palestinian adolescents from Ramallah district, including all social groups who live in urban, rural and refugee camps is a strength of this study. We were unable to include adolescents from other cities in the West Bank or Gaza Strip due to financial and political considerations. However, residents from all over the West Bank and to a lower extent from the Gaza strip tend to move to live and work in Ramallah since it is an economic centre in Palestine. This can, to some extent, overcome the issue of including just the Ramallah district in our study. HAS-A-AR can be used among 11-16-year-old Palestinian adolescents. However, the original HAS-A targeted a wider age group (12-19 years), and since the EFA revealed that HAS-A-AR has a similar structure to the original HAS-A we may consider that the HAS-A-AR is an appropriate instrument to use among this age group of Palestinian adolescents.

The meticulous translation process that involved experts with multiple revisions and the fact that adolescents faced no problems in understanding questions during interviews is another strength of this study. The addition of 
the extra options to the questionnaire to make it relevant to the Palestinian context and maybe to other countries in the Arab region is also the strength of this study. Since concerns regarding the reliability of self-reported scales were noted, ${ }^{11}$ conducting face-to-face interviews could be one of the reasons for the high response rate in our study especially that interviews were with adolescents who may not have completed a self-administered questionnaire as required. We used various tests that showed that HAS-A-AR has good psychometric properties. However, we could not perform test-retest reliability due to time and financial constraints. Additionally, we could not perform a criterion validity test as well due to the lack of a gold standard tool. Even though we performed CFA to confirm the results of EFA, we need to perform CFA using different samples in the future.

\section{CONCLUSION}

Health literacy research in Palestine is limited, and a locally validated tool for use among adolescents has been unavailable until now. This study demonstrates that HAS-A-AR has good construct validity and reliability. Thus, the HASA-AR is now available for use among adolescents in Palestine and the surrounding Arab countries that have similar characteristics as Palestine, including language, culture and political instability. Further research is needed to check for the other psychometric properties of the tool or to use the scale to evaluate and have a better understanding of adolescent health literacy and its associated factors. Moreover, it is important to conduct interventions or programmes (eg, within school settings) that aim to improve adolescent health literacy. It also seems necessary to invest in interventions targeting parents and doctors to improve how they communicate and deliver health information to adolescents and involve adolescents in the process of taking decisions related to their health.

Contributors Study design: MBAS, RF, MJ and RG. Direct supervision on data collection: MBAS and RG. Development and revision of methods and measures: MBAS, HS, RF, MJ and RG. Data analysis: MBAS. Revision of statistical analysis: HS. Interpretation: MBAS, HS, RF, MJ and RG. Writing of the first and final version of the manuscript: MBAS. Revision for important intellectual content: MBAS, HS, RF, MJ and RG. All authors approved the final version for publication.

Funding This work was supported by JSPS KAKENHI Grant No. 16KT0039.

Competing interests None declared.

Patient consent for publication Not required.

Ethics approval We obtained ethical approvals from the Research Ethics Committee of the Graduate School of Medicine, the University of Tokyo (ethical approval No. 11545-(1)) and The Research Ethics Committee (REC) of Birzeit University (ethical approval №. 161013).

Provenance and peer review Not commissioned; externally peer reviewed.

Data availability statement Data are available upon reasonable request.

Open access This is an open access article distributed in accordance with the Creative Commons Attribution Non Commercial (CC BY-NC 4.0) license, which permits others to distribute, remix, adapt, build upon this work non-commercially, and license their derivative works on different terms, provided the original work is properly cited, appropriate credit is given, any changes made indicated, and the use is non-commercial. See: http://creativecommons.org/licenses/by-nc/4.0/.
ORCID iDs

Mohammed B A Sarhan http://orcid.org/0000-0001-5130-4280

Masamine Jimba http://orcid.org/0000-0001-5659-3237

\section{REFERENCES}

1 Fadda M, Kanj M, Kabakian-Khasholian T, et al. Validation of three Arabic health literacy assessment tools in Lebanon. Health Promot Int 2018;33:261-7.

2 Almaleh R, Helmy Y, Farhat E, et al. Assessment of health literacy among outpatient clinics attendees at Ain Shams university hospitals, Egypt: a cross-sectional study. Public Health 2017;151:137-45.

3 Van den Broucke S. Health literacy: a critical concept for public health. Arch Public Health 2014;72:10.

4 Sørensen K, Van den Broucke S, Fullam J, et al. Health literacy and public health: a systematic review and integration of definitions and models. BMC Public Health 2012;12:80.

5 Abacigil $\mathrm{F}$, Harlak $\mathrm{H}$, Okyay $\mathrm{P}$, et al. Validity and reliability of the Turkish version of the European Health Literacy Survey Questionnaire. Health Promot Int 2019;34:658-67.

6 Sarhan M, Akiko K, Rika F, et al. Perceptions of adolescent health literacy in the Palestinian social context: a qualitative study. Jpn J Health Edu Promot 2019;27:29-42.

7 The World Health Organization (WHO). 9Th global conference on health promotion, Shanghai 2016, 2016. Available: https://www.who. int/healthpromotion/conferences/9gchp/en/ [Accessed 7 Feb 2020].

8 Paakkari L, Paakkari O. Health literacy as a learning outcome in schools. Health Educ 2012;112:133-52.

9 Bruselius-Jensen M, Bonde AH, Christensen JH. Promoting health literacy in the classroom. Health Educ J 2017;76:156-68.

10 Okan O, Bauer U. International Handbook of health literacy: research, practice and policy across the life-span. United Kingdom, Bristol: Policy Press, 2019.

11 Manganello JA, DeVellis RF, Davis TC, et al. Development of the health literacy assessment scale for adolescents (HAS-A). J Commun Healthc 2015;8:172-84.

12 Massey PM, Prelip M, Calimlim BM, et al. Contextualizing an expanded definition of health literacy among adolescents in the health care setting. Health Educ Res 2012;27:961-74.

13 Hagell A, Rigby E, Perrow F. Promoting health literacy in secondary schools: a review. Br J Sc Nurs 2015;10:82-7.

14 Maindal HT, Kayser L, Norgaard O, et al. Cultural adaptation and validation of the health literacy questionnaire (HLQ): robust ninedimension Danish language confirmatory factor model. Springerplus 2016;5:1232-32.

15 Guo S, Armstrong R, Waters E, et al. Quality of health literacy instruments used in children and adolescents: a systematic review. BMJ Open 2018;8:e020080.

16 Bröder J, Okan O, Bauer U, et al. Health literacy in childhood and youth: a systematic review of definitions and models. BMC Public Health 2017;17:361.

17 Ghanbari S, Ramezankhani A, Montazeri A, et al. Health literacy measure for adolescents (HELMA): development and psychometric properties. PLoS One 2016;11:e0149202.

18 Khajouei R, Salehi F. Health literacy among Iranian high school students. Am J Health Behav 2017;41:215-22.

19 Haney MO. Psychometric testing of the Turkish version of the health literacy for school-aged children scale. J Child Health Care 2018;22:97-107.

20 Tadakamadla SK, Quadri MFA, Pakpour AH, et al. Reliability and validity of Arabic rapid estimate of adult literacy in dentistry (AREALD-30) in Saudi Arabia. BMC Oral Health 2014;14:120.

21 Al-Jumaili AA, Al-Rekabi MD, Sorofman B. Evaluation of instruments to assess health literacy in Arabic language among Iraqis. Res Social Adm Pharm 2015;11:803-13.

22 Elsous A, Radwan M, Al-Sharif $\mathrm{H}$, et al. Medications adherence and associated factors among patients with type 2 diabetes mellitus in the Gaza Strip, Palestine. Front Endocrinol 2017;8:100-00.

23 Radwan M, Elsous A, Al-Sharif $\mathrm{H}$, et al. Glycemic control among primary care patients with type 2 diabetes mellitus in the Gaza Strip, Palestine. Ther Adv Endocrinol Metab 2018;9:3-14.

24 Waterston T, Nasser D. Access to healthcare for children in Palestine. BMJ Paediatr Open 2017;1:e000115.

25 Wild D, Grove A, Martin M, et al. Principles of good practice for the translation and cultural adaptation process for patient-reported outcomes (pro) measures: report of the ISPOR Task force for translation and cultural adaptation. Value Health 2005;8:94-104. 
26 Arafat SY, Chowdhury HR, Qusar M, et al. Cross cultural adaptation \& psychometric validation of research instruments: a methodological review. J Behav Health 2016;5:129-36.

27 Matsunaga M. How to factor-analyze your data right: do's, don'ts, and how-to's. Int. j. psychol. res. 2010;3:97-110.

28 Hayton JC, Allen DG, Scarpello V. Factor retention decisions in exploratory factor analysis: a tutorial on parallel analysis. Organ Res Methods 2004;7:191-205.

29 Comrey AL, Lee HB. A first course in factor analysis. Psychology press, 1992.

30 Jacobs NW, Berduszek RJ, Dijkstra PU, et al. Validity and reliability of the upper extremity work demands scale. J Occup Rehabil 2017;27:520-9.

31 Yong AG, Pearce S. A Beginner's Guide to Factor Analysis: Focusing on Exploratory Factor Analysis. Tutor Quant Methods Psychol 2013;9:79-94.

32 van Prooijen J-W, van der Kloot WA. Confirmatory analysis of exploratively obtained factor structures. Educ Psychol Meas 2001;61:777-92.

33 Streiner DL. A checklist for evaluating the usefulness of rating scales. Can J Psychiatry 1993;38:140-8.

34 Dunn TJ, Baguley T, Brunsden V. From alpha to omega: a practical solution to the pervasive problem of internal consistency estimation. Br J Psychol 2014;105:399-412.

35 Trizano-Hermosilla I, Alvarado JM. Best alternatives to Cronbach's alpha reliability in realistic conditions: congeneric and asymmetrical measurements. Front Psychol 2016;7:769-69.

36 Hair JF, Black WC, Babin BJ, et al. Multivariate data analysis. 7th ed. England: Pearson, 2014.

37 Piedmont RL, Correlations I-item. In: Michalos AC, ED. encyclopedia of quality of life and well-being research. Dordrecht: Springer Netherlands 2014:3303-4.

38 Briggs SR, Cheek JM. The role of factor analysis in the development and evaluation of personality scales. J Pers 1986;54:106-48.

39 Robins RW, Fraley RC, Krueger RF. Handbook of research methods in personality psychology. Guilford Press, 2007.
40 Ladhari R. Developing e-service quality scales: a literature review. J Retail Consum Serv 2010;17:464-77.

$41 \mathrm{Kang} \mathrm{H}$. The prevention and handling of the missing data. Korean $\mathrm{J}$ Anesthesiol 2013;64:402.

42 Borsa JC, Damásio BF, Bandeira DR. Cross-cultural adaptation and validation of psychological instruments: some considerations. Paidéia 2012;22:423-32.

43 Pinder KE. The effects of ordinal data on coefficient alpha. James Madison University 2015.

44 Revelle W, Zinbarg RE, alpha C. Beta, omega, and the glb: comments on Sijtsma. Psychometrika 2009;74:145.

45 Viladrich C, Angulo-Brunet A, Doval E. A journey around alpha and omega to estimate internal consistency reliability. An Psicol-Spain 2017;33:755-82.

46 Chakraborty R. Estimation of greatest lower bound reliability of academic delay of Gratification scale. IOSR-JRME 2017.

47 Clark LA, Watson D. Constructing validity: basic issues in objective scale development. Psychol Assess 1995;7:309-19.

48 Grootens-Wiegers P, Hein IM, van den Broek JM, et al. Medical decision-making in children and adolescents: developmental and neuroscientific aspects. BMC Pediatr 2017;17:120-20.

49 McKenna VB, Sixsmith J, Barry MM. The relevance of context in understanding health literacy skills: findings from a qualitative study. Health Expect 2017;20:1049-60.

50 Grootens-Wiegers P, Visser EG, van Rossum AMC, et al. Perspectives of adolescents on decision making about participation in a Biobank study: a pilot study. BMJ Paediatr Open 2017;1:e000111.

51 Schaeuble K, Haglund K, Vukovich M. Adolescents' preferences for primary care provider interactions. J Spec Pediatr Nurs 2010;15:202-10.

52 Croom A, Wiebe DJ, Berg CA, et al. Adolescent and parent perceptions of patient-centered communication while managing type 1 diabetes. J Pediatr Psychol 2011;36:206-15. 